\title{
Epileptic spasms in congenital disorders of glycosylation
}

\author{
Andreia G. Pereira ${ }^{1}$, Nadia Bahi-Buisson ${ }^{2,3}$, \\ Christine Barnerias ${ }^{2}$, Nathalie Boddaert ${ }^{4,5}$, Rima Nabbout ${ }^{2}$, \\ Pascale de Lonlay 6,7, Anna Kaminska ${ }^{8,9}$, Monika Eisermann ${ }^{8,9}$ \\ ${ }^{1}$ Pediatric Neurology Service, Dona Estefânia Hospital, \\ Centro Hospitalar Lisboa Central, EPE, Lisbon, Portugal \\ ${ }^{2}$ Department of Pediatric Neurology, Necker Enfants Malades Hospital, Paris \\ 3 INSERM U781, Paris Descartes University, Paris \\ ${ }^{4}$ Pediatric Radiology Department, Necker Enfants Malades Hospital, Paris \\ ${ }^{5}$ INSERM UMR1163 and U1000, Institut Imagine, Paris Descartes University, Paris \\ ${ }^{6}$ Center of Metabolism, Necker Enfants Malades Hospital, Paris \\ ${ }^{7}$ Institut Imagine, Paris Descartes University APHP, Paris \\ ${ }^{8}$ Department of Clinical Neurophysiology, Necker Enfants Malades Hospital, Paris \\ 9 INSERM U1129, Paris, France; Paris Descartes University, CEA, Gif sur Yvette, Paris, \\ France
}

Received May 03, 2016; Accepted December 01, 2016

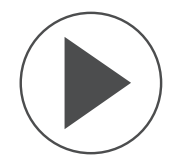

VIDEO ONLINE

Correspondence:

Andreia Gomes Pereira

Centro de Neurologia,

Reabilitação Pediátrica e

Desenvolvimento Infantil,

Serviço de Pediatria,

Centro Hospitalar do Algarve-Unidade

de Faro,

Rua Leão Penedo,

8000 Faro, Portugal

<andgpereira@gmail.com>
ABSTRACT - Aim. Congenital disorders of glycosylation (CDG) are a group of rare metabolic diseases, characterized by impaired glycosylation. Multisystemic involvement is common and neurological impairment is notably severe and disabling, concerning the central and peripheral nervous system. Epilepsy is frequent, but detailed electroclinical description is rare. Methods. We describe, retrospectively, the electroclinical features in five children with CDG and epileptic spasms.

Results. Epileptic spasms were observed in patients with ALG1-, ALG6, ALG11-CDG and CDG-Ix, and occurred at an early age, before 6 months in all cases, except one who had spasms that started at 18 months. In this patient, spasms had an unusual aspect; they did not occur in clusters and were immediately preceded by a myoclonus. All but one child also presented rare myoclonias. On EEG, background activity was poorly organized with abundant posterior spike and fast rhythm activity, but without hypsarrhythmia. At the last evaluation (age range: 6-12 years), two patients still presented epileptic spasms and subcortical myoclonias, one showed rare generalized tonic-clonic seizures, and two were seizure-free.

Conclusion. CDG disorders can be associated with epileptic spasms showing particular features, such as absence of hypsarrhythmia, posterior EEG anomalies, and an unusual combination of epileptic spasms with myoclonus. These features, associated with pre-existing developmental delay and subcortical myoclonias, may shift toward CDG screening. [Published with video sequence and supplemental EEG plates on www.epilepticdisorders.com]

Key words: congenital disorders of glycosylation, epilepsy, epileptic spasms, myoclonus 
Since their first description in 1980 (Jaeken et al., 1980), congenital disorders of glycosylation (CDG) are still a rare but rapidly expanding family of inherited diseases, nowadays including over 70 identified autosomal recessive genetic disorders (Freeze et al., 2012; Barone et al., 2014).

Biochemically, these disorders are characterized by impaired glycosylation of proteins and lipids, caused by mutations in genes required for the synthesis of the glycan moiety or for the attachment of these glycans to proteins and lipids. According to their specific pattern on transferrin isoelectric focusing (TIEF), CDGs are divided into two groups. CDG type I comprise defects in the biosynthesis of dolichol-linked oligosaccharides in the cytosol or the endoplasmic reticulum, as well as defects involving the transfer of oligosaccharides onto nascent glycoproteins. CDG type II encompass all defects of further trimming and elongation of $\mathrm{N}$ linked oligosaccharides in the endoplasmic reticulum and the Golgi apparatus (Schwarz et al., 2004; Jaeken, 2010,2012 ). Following a recent revision of the nomenclature (Jaeken et al., 2009), CDG subtyping is now based on the affected gene.

The exact prevalence of this group of disorders is unknown. There are approximately 1,000 cases published in the literature (Vodopiutz and Bodamer, 2008; Dupré et al., 2010). Of the CDG forms identified worldwide, $80 \%$ correspond to phosphomannomutase (PMM) 2 deficiency (PMM2-CDG or CDG-la) (Jaeken, 2010; Freeze et al., 2012). Phosphomannose-isomerase (MPI) deficiency (MPI-CDG) and glucosyltransferase I (ALG6) deficiency (ALG6-CDG), referred to as CDG-Ib and CDG-Ic, respectively, have been reported in more than 60 individuals worldwide (Jaeken, 2010).

However, in France, PMM2-CDG represents $62 \%$ of diagnosed CDG families, followed by MPI-CDG (6\%), ALG1-CDG (mannosyltransferase 1 [MT-1] deficiency) or CDG Ik (6\%), and ALG6-CDG (4\%). About $15 \%$ of CDG families have a yet unidentified glycosylation defect, and thus remain to be subtyped, under the designation of CDG Ix (Dupré et al., 2010).

Because of the fundamental biological role of glycoproteins, impaired glycosylation mechanisms lead to multisystemic involvement and thus to a broad spectrum of clinical features (de Lonlay et al., 2001; Vodopiutz and Bodamer, 2008; Morava et al., 2008; Funke et al., 2013). Neurological impairment is often severe and disabling and includes structural abnormalities, such as rapidly progressive cerebellar atrophy and cortical atrophy, myopathies including congenital muscular dystrophies and limb-girdle dystrophies, seizures, stroke and "stroke-like" episodes, developmental delay, and demyelinating neuropathy (de Lonlay et al., 2001; Drouin-Garraud et al., 2001;
Grubenmann et al., 2004; Kranz et al., 2004; Jaeken, 2010; Freeze et al., 2012; Rahman et al., 2013).

Since CDG is a rare disorder, the exact incidence of epilepsy in these patients is yet to be determined, ranging from 0 (patients with only visceral disease) to $100 \%$ (patients with severe forms of neurological impairment). This also appears to correlate to the underlying genetic defect (de Lonlay et al., 2001; Morava et al., 2008; Dupré et al., 2010). Epilepsy is uncommon in the most frequent form of CDG, PMM2-CDG, but frequently present in other types of CDG (Fiumara et al., 2016). Seizures can begin from the neonatal period to later childhood and are described either as easily manageable or pharmacoresistant (de Lonlay et al., 2001; Clayton and Grunewald, 2009; Dupré et al., 2010; Jaeken, 2010; Freeze et al., 2012; Funke et al., 2013; Fiumara et al., 2016; OMIM database).

CDG disorders are considered as one of the underlying aetiologies for early-onset epilepsy and inborn errors of metabolism (Wolf et al., 2005; Bahi-Buisson et al., 2006; Fois, 2010; Noh et al., 2012; Rahman et al., 2013; Fiumara et al., 2016). However, detailed characterization of seizure semiology and neurophysiological patterns is rare. We report the presence of epileptic spasms without hypsarrhythmia in five children with CDG syndrome.

\section{Methods}

Among the patients with CDG syndrome followed in the Pediatric Neurology and the Metabolism Department in Necker Enfants Malades Hospital, Paris, France, polygraphic video-EEG recordings performed between 2000 and 2013 in the Neurophysiology Department of the same hospital revealed, in five children, the presence of epileptic spasms. We retrospectively studied their clinical data, epileptic manifestations, and EEG findings.

In all patients, TIEF showed a type I pattern of serum transferrin, and molecular studies revealed three different mutations in four of the five children (table 1). All patients had undergone one to 11 polygraphic video-EEG recordings in the Necker Enfants Malades Hospital.

Video-EEG recordings included polygraphic parameters, such as electrocardiogram (ECG), respiration measurements, and surface electromyography (EMG). The number of electrodes (silver chloride cup electrodes) was chosen depending on age and head size (ranging from 9 to 21) and placed according to the 10/20 international system using the medial frontal polar $(\mathrm{FPz})$ as reference electrode. EMG was recorded by two cup electrodes placed $2 \mathrm{~cm}$ apart on one or both deltoid muscles. Recordings lasted at least one hour up 
to 24 hours. Signals were amplified $(x 1,000)$, band-pass filtered at $0.01-97 \mathrm{~Hz}$, and digitized at $256 \mathrm{~Hz}$ using the Deltamed Coherence EEG system (Deltamed/Natus Paris, France).

\section{Results}

\section{Patient 1}

Patient 1 was an 11-year-old female and the third child to healthy, unrelated parents. Two aunts (on the father's side) with psychomotor delay of unknown aetiology died during infancy; both were born at term with uneventful pregnancy. From birth onwards, feeding difficulties, poor eye contact, pendulum eye movements, and severe global hypotonia were observed. Segmental myoclonias started at the age of 2 months; at 4 months of age, she presented clusters of flexor spasms, described as asymmetric, upon awakening and during drowsiness that could be decreased in frequency by anticonvulsant therapy (vigabatrin, hydrocortisone, and topiramate).

Studies of metabolic blockage and enzyme activity revealed a deficiency in MT-1 and a molecular study confirmed the diagnosis of ALG1-CDG.

The video-EEG recording performed at the age of 9 months (under treatment with vigabatrin, hydrocortisone, and topiramate) showed a preserved, although slow for age, background activity, with occipital anomalies predominating on the right side without any hypsarrhythmia (supplementary figures 1A, 2A). During sleep, the recorded distal hand and feet myoclonias had no EEG correlate. During awakening, a long-lasting cluster of spasms was recorded with typical EEG features, but with very subtle clinical manifestations (see video sequence [at 5 seconds] and supplementary figure 3 ).

\section{Patient 2}

Patient 2 was a 10 -year-old male and a first child to unrelated parents. Pregnancy was complicated by maternal hypertension and foetal growth retardation. Absent eye contact, psychomotor retardation, and severe axial hypotonia, as well as pyramidal signs were noted in the first three months of life. At the age of 4 months, he started with clusters of symmetric flexion spasms upon awakening. A few months later, in addition to spasms, daily generalized tonic seizures and very frequent distal myoclonias, particularly during sleep, occurred. Spasms responded to vigabatrin treatment, but segmental myoclonic jerks concerning the head and shoulders persisted and severe encephalopathy with spastic tetraplegia was established.
Studies of metabolic blockage and enzyme activity revealed a deficiency in MT-1 and a molecular study of the ALG1 gene confirmed the diagnosis of ALG1-CDG. Eleven polygraphic video-EEGs were recorded between the age of 13 months and 7 years. Awake and sleep EEG showed abundant occipital anomalies (supplementary figures $1 B, 2 B$ ). At the age of 18 months, a long-lasting (15-minute) cluster of epileptic spasms on arousal was recorded (see video sequence [at 4 minutes] and supplementary figure 4). Myoclonic jerks had no EEG correlate. The posterior anomalies persisted after cessation of spasms.

\section{Patient 3}

Patient 3 was a 12-year-old male, and a third child to healthy, unrelated parents. One older brother (born in 1996) presented the same disorder. The patient had moderate hydramnios during the third trimester of pregnancy; he was born at term. Since early life, feeding difficulties were noted, as well as an absence of eye contact, severe global hypotonia, and pyramidal signs. At the age of 6 months, he started having daily clusters of spasms upon awakening and frequent segmental myoclonic jerks. Despite several antiepileptic treatments (vigabatrin, hydrocortisone, valproic acid, topiramate, clonazepam, and clobazam), spasms and myoclonic jerks persisted, as well as severe axial hypotonia, pyramidal signs, severe psychomotor retardation, and agitated behaviour.

A molecular study revealed two allelic mutations in the ALG6 gene, confirming the diagnosis of ALG6-CDG.

Four polygraphic video-EEGs were recorded between 11 and 21 months of age, disclosing an occipital polyrhythmic background activity with bilateral independent posterior spikes and sharp waves (supplementary figures 1C, 2C). Frequent segmental non-epileptic myoclonias were noted.

At the age of 11 nbsp;months, a cluster of typical symmetric epileptic spasms was recorded after awakening, lasting for 30 minutes, as well as one isolated tonic spasm (see video sequence [at 6 minutes, 14 seconds] and supplementary figures 5 and 6). Posterior anomalies persisted and at the age of 21 months, these were also recorded as subclinical rhythmic sequences (supplementary figure 7).

\section{Patient 4}

Patient 4 was a 14-year-old male, and an only child of consanguineous parents. The patient had an unremarkable pregnancy, and was born at full term. Developmental delay was described, with late head control and free walking at the age of 2 years. 
Table 1. Electroclinical features of 5 CDG patients presenting epileptic spasms, followed in Necker-Enfants Malades Hospital, Paris, between 2000 and 2013.

\begin{tabular}{|c|c|c|c|c|c|}
\hline & Patient 1 & Patient 2 & Patient 3 & Patient 4 & Patient 5 \\
\hline Actual age & 10 years & 11 years & 12 years & 14 years & 6 years \\
\hline $\begin{array}{l}\text { Age at last } \\
\text { evaluation }\end{array}$ & 10 years & 11 years & 4 years & 14 years & 6 years \\
\hline Gender & Female & Male & Male & Male & Female \\
\hline CDG subtype & $\begin{array}{l}\text { ALG1-CDG } \\
(\mathrm{CDG} \text { Ik) }\end{array}$ & $\begin{array}{l}\text { ALG1-CDG } \\
\text { (CDG Ik) }\end{array}$ & $\begin{array}{l}\text { ALG6-CDG } \\
\text { (CDG Ic) }\end{array}$ & CDG Ix & $\begin{array}{l}\text { ALG11-CDG } \\
\text { (CDG 1p) }\end{array}$ \\
\hline $\begin{array}{l}\text { Age at } \\
\text { diagnosis } \\
\text { of CDG }\end{array}$ & 1 year (2006) & 2 years (2006) & 1 year (2004) & 4 years & 1 year \\
\hline $\begin{array}{l}\text { Complication } \\
\text { during } \\
\text { pregnancy }\end{array}$ & None & $\begin{array}{l}\text { Maternal } \\
\text { hypertension, } \\
\text { foetal growth } \\
\text { retardation }\end{array}$ & $\begin{array}{l}\text { Moderate } \\
\text { hydramnios }\end{array}$ & None & None \\
\hline $\begin{array}{l}\text { Early feeding } \\
\text { difficulties }\end{array}$ & Yes & No & Yes & No & No \\
\hline $\begin{array}{l}\text { Muscular } \\
\text { hypotonia }\end{array}$ & Yes & Yes & Yes & Yes & Yes \\
\hline $\begin{array}{l}\text { Early pyramidal } \\
\text { signs }\end{array}$ & Yes & Yes & Yes & Yes & Yes \\
\hline Microcephaly & Yes (-4SD) & Yes & Yes (-3.5SD) & No & Yes (-3SD) \\
\hline $\begin{array}{l}\text { Age at the } \\
\text { beginning } \\
\text { of spasms }\end{array}$ & 4 months & 4 months & 6 months & 18 months & 5 months \\
\hline Myoclonias & $\begin{array}{l}\text { Segmental } \\
\text { non-epileptic } \\
\text { myoclonias }\end{array}$ & $\begin{array}{l}\text { Segmental } \\
\text { non-epileptic } \\
\text { myoclonus; very } \\
\text { rare discrete } \\
\text { cortical } \\
\text { myoclonias only } \\
\text { in sleep at the } \\
\text { age of } 2 \text { years }\end{array}$ & $\begin{array}{l}\text { Segmental } \\
\text { non-epileptic } \\
\text { myoclonus }\end{array}$ & $\begin{array}{l}\text { Cortical } \\
\text { myoclonias }\end{array}$ & None \\
\hline $\begin{array}{l}\text { Other seizure } \\
\text { types }\end{array}$ & Febrile GTCS & Tonic seizures & None & $\begin{array}{l}\text { Rare tonic and } \\
\text { tonic-clonic } \\
\text { seizures during } \\
\text { sleep; isolated, } \\
\text { multifocal, } \\
\text { cortical } \\
\text { myoclonias }\end{array}$ & $\begin{array}{l}\text { Focal clonic } \\
\text { seizures }\end{array}$ \\
\hline
\end{tabular}


Table 1. Electroclinical features of 5 CDG patients presenting epileptic spasms, followed in Necker-Enfants Malades Hospital, Paris, between 2000 and 2013. (Continued).

\begin{tabular}{|c|c|c|c|c|c|}
\hline & Patient 1 & Patient 2 & Patient 3 & Patient 4 & Patient 5 \\
\hline EEG & $\begin{array}{l}\text { Posterior theta } \\
\text { rhythm, } \\
\text { interposed } \\
\text { with } \\
\text { high-voltage } \\
\text { and slow delta } \\
\text { waves } \\
\text { predominating } \\
\text { on the right } \\
\text { side, rare } \\
\text { posterior } \\
\text { spikes. } \\
\text { Absence of } \\
\text { physiological } \\
\text { sleep } \\
\text { graphoele- } \\
\text { ments. }\end{array}$ & $\begin{array}{l}\text { Posterior theta } \\
\text { delta rhythm; } \\
\text { abundant } \\
\text { bilateral } \\
\text { high-voltage } \\
\text { spikes and } \\
\text { spike wave } \\
\text { activity in } \\
\text { posterior } \\
\text { regions. } \\
\text { Absence of } \\
\text { physiological } \\
\text { sleep figures. }\end{array}$ & $\begin{array}{l}\text { Polyrhythmic } \\
\text { background } \\
\text { with posterior } \\
\text { theta and delta } \\
\text { rhythm; rare } \\
\text { bilateral } \\
\text { independent } \\
\text { posterior } \\
\text { spikes and } \\
\text { sharp waves. }\end{array}$ & $\begin{array}{l}\text { Disorganized } \\
\text { slow theta } \\
\text { background } \\
\text { activity, } \\
\text { physiological } \\
\text { sleep figures } \\
\text { present. }\end{array}$ & $\begin{array}{l}\text { Posterior } \\
\text { high-voltage } \\
\text { theta delta } \\
\text { rhythm; } \\
\text { abundant } \\
\text { bilateral high } \\
\text { voltage spikes } \\
\text { and spike wave } \\
\text { activity in } \\
\text { posterior } \\
\text { regions. } \\
\text { Absence of } \\
\text { physiological } \\
\text { sleep figures. }\end{array}$ \\
\hline $\begin{array}{l}\text { Seizure } \\
\text { evolution }\end{array}$ & $\begin{array}{l}\text { Persistence of } \\
\text { epileptic } \\
\text { spasms and } \\
\text { distal } \\
\text { myoclonias. }\end{array}$ & $\begin{array}{l}\text { Cessation of } \\
\text { epileptic } \\
\text { spasms (since } \\
2 / 2014 \text { ), } \\
\text { persistence of } \\
\text { rare segmental } \\
\text { myoclonias }\end{array}$ & $\begin{array}{l}\text { Persistence of } \\
\text { epileptic } \\
\text { spasms and } \\
\text { distal } \\
\text { myoclonias }\end{array}$ & $\begin{array}{l}\text { Rare GTCS, no } \\
\text { jerks }\end{array}$ & $\begin{array}{l}\text { Cessation of } \\
\text { epileptic } \\
\text { spasms (since } \\
6 / 2013 \text { ) }\end{array}$ \\
\hline Cranial MRI & $\begin{array}{l}\text { (At the age of } 6 \\
\text { months): } \\
\text { normal } \\
\text { myelination, } \\
\text { discrete } \\
\text { supratentorial } \\
\text { atrophy, } \\
\text { moderately } \\
\text { thin corpus } \\
\text { callosum, no } \\
\text { posterior fossa } \\
\text { abnormalities }\end{array}$ & $\begin{array}{l}\text { Hypomyelination } \\
\text { (or important } \\
\text { abnormal } \\
\text { myelination) at } \\
\text { infra and } \\
\text { supratentorial } \\
\text { areas. } \\
\text { Moderate } \\
\text { cerebellar } \\
\text { atrophy. Thin } \\
\text { corpus } \\
\text { callosum. }\end{array}$ & $\begin{array}{l}\text { (At the age of } 7 \\
\text { months): } \\
\text { discrete } \\
\text { myelination } \\
\text { delay; no } \\
\text { posterior fossa } \\
\text { abnormalities }\end{array}$ & $\begin{array}{l}\text { Normal } \\
\text { myelination, } \\
\text { normal } \\
\text { configuration } \\
\text { of the } \\
\text { posterior fossa, } \\
\text { moderate } \\
\text { ventricular } \\
\text { dilatation. }\end{array}$ & $\begin{array}{l}\text { Pericerebral } \\
\text { collection or } \\
\text { enlarged } \\
\text { subarachnoids } \\
\text { spaces. } \\
\text { Normal } \\
\text { myelination } \\
\text { and normal } \\
\text { posterior fossa. }\end{array}$ \\
\hline Evolution & $\begin{array}{l}\text { Severe } \\
\text { psychomotor } \\
\text { retardation, } \\
\text { spastic } \\
\text { tetraplegia }\end{array}$ & $\begin{array}{l}\text { Severe } \\
\text { psychomotor } \\
\text { retardation, no } \\
\text { head control }\end{array}$ & $\begin{array}{l}\text { Severe } \\
\text { psychomotor } \\
\text { retardation }\end{array}$ & $\begin{array}{l}\text { Free walking, } \\
\text { language delay, } \\
\text { good } \\
\text { interaction, } \\
\text { behaviour } \\
\text { problems } \\
\text { (heteroaggres- } \\
\text { sivity) }\end{array}$ & $\begin{array}{l}\text { Severe } \\
\text { psychomotor } \\
\text { retardation, } \\
\text { spastic } \\
\text { tetraplegia. }\end{array}$ \\
\hline
\end{tabular}

GTCS: generalized tonic-clonic seizure; SD: Standard deviation. 
At the age of 18 months, massive jerks started, as well as rare generalized tonic or tonic-clonic seizures during sleep. Antiepileptic therapy (phenobarbital, levetiracetam, clonazepam, clobazam, and lamotrigine) controlled seizures only partially. At the age of 11 years, severe language retardation, agitated behaviour, pyramidal syndrome, and strabismus were present.

Studies for enzymatic activity associated with CDG were normal and the molecular study of CDG genes failed to identify any mutation, establishing the diagnosis of CDG Ix.

Five video-EEGs were performed between 4 and 8 years of age.

Interictal EEG showed slow, disorganized background activity, but physiological sleep graphoelements without interictal paroxysmal anomalies (supplementary figure 8).

At the age of 4 years, seizures were recorded during wakefulness or drowsiness; isolated segmental cortical myoclonias and massive jerks evoking into epileptic spasms, although with unusual components (see video sequence [10 minutes, 18 seconds] and supporting figure 9). At the age of 11 years, seizures were poorly controlled and development severely delayed, associated with an aggressive and impulsive behaviour, however, with the ability to walk alone and to speak a few words.

\section{Patient 5}

Patient 5 was a 4-year-old female, and a first child of healthy, unrelated parents. The patient was born at term, after an uneventful pregnancy. Since early life, absent eye contact and global hypotonia were described. At the age of 5 months, epileptic spasms occurring in long-lasting clusters were observed, as well as long-lasting focal clonic seizures, which were pharmacoresistant (to vigabatrine, hydrocortisone, ACTH, carbamazepine, topiramate, clobazepam, clonazepam, stiripentol, and zonisamide). After the introduction of a ketogenic diet at the age of 23 months, spasms diminished rapidly with regards to frequency and duration of clusters, and occurred as isolated jerks which then completely disappeared. Antiepileptic treatment could slowly be reduced and stopped.

A molecular study confirmed the diagnosis of ALG11CDG.

Five video-EEGs were performed between 9 months and 2 years of age.

Interictal EEG showed slow, disorganized background activity with very abundant bilateral independent occipital anomalies (supplementary figures 1D, 2D). At the age of 2 years, spasms were recorded, either isolated or in short clusters of 3-5, and sometimes, as seen in Patient 4, with an unusual aspect associated with two distinct phases (see video sequence [11 minutes, 38 seconds] and supplementary figures 10 and 11).

\section{Discussion}

We report five children presenting epileptic spasms without hypsarrhythmia associated with various CDG syndromes. Despite the fact that epilepsy is one of the main neurological features described in CDG patients, detailed characterization of ictal semiology and neurophysiological patterns is rare (de Lonlay et al., 2001; Morava et al., 2008; Clayton and Grunewald, 2009; Dupré et al., 2010; Jaeken, 2010; Freeze et al., 2012; Funke et al., 2013; Fiumara et al, 2016), and epileptic spasms without hypsarrhythmia associated with myoclonus have not yet been reported.

Epileptic spasms showed a typical EEG pattern in all patients, associated with particular features including only subtle motor manifestations, more sustained contractions, chewing movements, a combination of myoclonus and spasm, or a marked asynchrony and asymmetry. In contrast, typical hypsarrhythmia was never present during wakefulness or sleep.

Patients 1 and 2 (corresponding to two of the five patients described by Dupré et al., 2010), both suffering from ALG1-CDK, started epileptic spasms at 4 months of age; the seizures in Patient 1 were pharmacoresistant. EEG showed very abundant occipital anomalies. Severe, refractory epilepsy has been previously described in ALG1-CDG (Clayton and Grunewald, 2009; Dupré et al., 2010; Jaeken, 2010; Freeze et al., 2012). All of the 11 ALG1-CDG patients published so far had "severe", "multifocal", "refractory" seizures or presented with an "early epileptic encephalopathy" (Grubenmann et al., 2004; Kranz et al., 2004; Dupré et al., 2010; Fiumara et al, 2016). EEG was reported as "abnormal" in four children, "multifocal" in one child, and "with electroclinical features of Ohtahara syndrome" in another (Grubenmann et al., 2004; Kranz et al., 2004; Dupré et al., 2010; Fiumara et al, 2016). The presence of epileptic spasms in this population, however, has never been described.

Concerning ALG6-CDG, the patient described here started refractory, generalized tonic seizures and clusters of epileptic spasms at 6 months of age. Similar to ALG1-CDG, there was no hypsarrhythmia and also very abundant interictal posterior anomalies. The majority of the 54 ALG6-CDG patients published so far (Haeuptle and Hennet, 2009; Ishikawa et al., 2009; Dercksen et al., 2012; Fiumara et al, 2016; Jaeken et al., 2015) also had early-onset epilepsy. However, few publications describe seizures types and EEG tracings. Grunewald et al. (2000) reported eight patients with: febrile seizures (3/8), atonic seizures (2/8), myoclonic 
seizures (2/8), generalized tonic-clonic seizures (1/8), as well as normal interictal EEG findings (6/8). Some case reports (Sun et al., 2005; Ishikawa et al., 2009; AlOwain et al., 2010; Dercksen et al., 2012; Fiumara et al, 2016) also describe "severe epilepsy", febrile seizures, generalized seizures, complex partial seizures, atonic and myoclonic seizures, as well as generalized tonicclonic seizures. EEG is, in some children, reported as "abnormal" (Dercksen et al., 2012), but not further detailed. Overall, in the literature, many different seizure types in ALG6-CDG patients are reported, but epileptic spasms have not been described so far.

Our patient with ALG11-CDG presented typical epileptic spasms that were either in very long-lasting clusters or isolated, as well as very abundant posterior anomalies, but also focal clonic seizures and rare isolated massive jerks with a combination of myoclonus and spasm. Only four patients with ALG11-CDG subtype have been published so far (Rind et al., 2010; Thiel et al., 2012). Seizures were present in all children, but not further detailed, and EEG was described with generalized epileptic activity. Patients presented with early feeding difficulties, muscular hypotonia, and early-onset seizures.

Electroclinical presentation in our patient with CDG Ix was different compared to the other patients. EEG background activity was very slow and amplified, showing multifocal anomalies but preserved features of sleep. Seizures began later, at the age of 18 months, and consisted of tonic and tonic-clonic seizures, as well as sudden massive jerks, presenting as a combination of myoclonus and spasm. So far, 25 patients with CDG Ix have been described (Morava et al., 2008, Millón et al., 2011), presenting very heterogeneous clinical features. Epilepsy is reported in seven of them, but seizure types and EEG features are not detailed.

Epileptic spasms in the context of CDG have only been described in a case report of two siblings with dolichol kinase (DOLK) deficiency (DOLK-CDG or CDG- $I m$ ). Both started spasms at the age of 4 months (Helander et al., 2013), with typical hypsarrhythmia on EEG. Both children presented other seizure types, such as generalized tonic-clonic and focal seizures, with complete seizure control which was easily obtained. Psychomotor retardation was less severe compared to our patients with free sitting at the age of 2 years and walking and bike riding at the age of 10 years.

Epileptic spasms in the absence of hypsarrhythmia have, to our knowledge, never been reported in CDG, and were, in our patients, associated with ALG1-, ALG6-, ALG11-CDG and CDG Ix subgroups. Interestingly, none of the 31 patients suffering from PMM2-CDG followed at our hospital presented epileptic spasms. Seizures in these patients occurred in one third (11/31), at an older age (medium: 4 years), and in $75 \%$ cases associated with fever, either (6/11) as brief generalized tonic-clonic events or prolonged focal seizures which often revealed a stroke-like episode (personal data; in preparation).

Absence of hypsarrhythmia in the presence of epileptic spasms was described in cortical lesions as focal cortical dysplasia or tubers in tuberous sclerosis complex (Dulac et al., 2002; Caraballo et al., 2003, 2011). In four of our five patients with CDG syndrome, common features included abundant occipital spikes, polyspikes, and fast rhythmic bursts with lateralization. Together with asymmetry and asynchrony of spasms, as well as focal seizures in one child, posterior structural anomalies were suspected before the diagnosis of glycosylation disorder. This was further underlined by the presence of associated symptomatology during the clusters with behavioural changes, chewing movements, facial fear expression, and hypersalivation. However, brain MRI did not disclose any focalized cerebral lesion in any of the patients.

In conclusion, our data show that epileptic spasms, notably when associated with myoclonus, are a possible feature of epilepsy in non-PMM2-CDG and exhibit particular EEG patterns which should be taken into consideration when investigating a child with epileptic spasms. For children diagnosed with CDG, we recommend polygraphic video-EEG recording for precise identification and characterization of seizures, allowing for more specific antiepileptic treatment. In addition, for children presenting with severe psychomotor retardation, microcephaly, epileptic spasms, together with interictal posterior anomalies without underlying focal MRI lesion, screening for CDG disorders should be considered.

\section{Supplementary data.}

Summary didactic slides and supplementary figures are available on the www.epilepticdisorders.com website.

\section{Acknowledgements and disclosures.}

This work was not supported by a grant or otherwise. None of the authors have any conflict of interest to disclose. 


\section{Legend for video sequence}

Patient 1. A 9-month-old girl with a long-lasting cluster of spasms (lasting for 7 minutes) upon awakening. Clinical manifestations of spasms are subtle, consisting of very discrete elevation of the shoulders and extension of arms, accompanied by discrete activity arrest and/or eye revulsion. In between the spasms, the child shows chewing movements and in the second part of the cluster, crying. Some discrete distal myoclonias of both arms are apparent. EMG1: right deltoid; EMG2: left deltoïd.

Patient 2. An 18-month-old boy with a long-lasting cluster of spasms upon awakening, with cortical myoclonias in sleep. At the start, there are discrete eye revulsion movements, progressively accompanied by motor manifestations consisting of asymmetric (predominately of the right arm) and asynchronous brief jerks concerning the head, shoulders, trunk, and arms. During the whole cluster, the child appears frightened and demonstrates chewing movements between the jerks. EMG2: right deltoid; ECG: left deltoid.

Patient 3. An 11-month-old boy with a long-lasting cluster of spasms upon awakening. Discrete motor manifestations consisting of flexion of both legs, associated with extension of the arms and movements of the head, are apparent. Between spasms, the patient demonstrates chewing movements and salivation. EMG1: right deltoid; EMG2: left deltoïd.

Patient 4. A 4-year-old boy with four isolated massive jerks with sudden extension of the arms and legs, accompanied by eye revulsion and head deviation towards the right side, followed by chewing movements, during sleep or wakefulness. Cortical myoclonus in sleep is also apparent. EMG2: right deltoid; ECG: left deltoid

Patient 5. A 2-year-old girl with discrete brief tonic contractions with extension of the four limbs, sometimes predominating over the right arm and left leg, associated with eye revulsion, either isolated or in series. Isolated jerks with subtle extension of both arms and massive flexion of both legs, accompanied by eye revulsion, are also apparent. EMG2: right deltoid; ECG: left deltoid.

\section{Key words for video research on www.epilepticdisorders.com}

Phenomenology: myoclonus, spasms

Localisation: occipital

Epilepsy syndrome: epileptic spasms

Aetiology: congenital disorders of glycosylation

\section{References}

Al-Owain M, Mohamed S, Kaya N, et al. A novel mutation and first report of dilated cardiomyopathy in ALG6-CDG (CDGIC): a case report. Orphanet J Rare Dis 2010; 5: 7-11.

Barone R, Fiumara A, Jaeken J. Congenital disorders of glycosylation with emphasis on cerebellar involvement. Semin Neurol 2014; 34(3): 357-66.

Bahi-Buisson N, Mention K, Léger PI K, et al. Épilepsies néonatales et erreurs innées du métabolisme. Arch Pediatr 2006; 13: 284-92.

Caraballo RH, Fejerman N, Dalla Bernardina B, et al. Epileptic spasms in clusters without hypsarrhythmia in infancy. Epileptic Disord 2003; 5: 109-13.

Caraballo RH, Ruggieri V, Gonzalez G, et al. Infantile spasms without hysparrhythmia: a study of 16 cases. Seizure 2011; 20: 197-202.

Clayton PT, Grunewald S. Comprehensive description of the phenotype of the first case of congenital disorder of glycosylation due to RFT1 deficiency (CDG In). J Inherit Metab Dis 2009; 32(1): 137-9.

Dercksen M, Crutchley AC, Honey EM, et al. ALG6-CDG in South Africa: genotype-phenotype description of five novel patients. J Inherit Metab Dis 2012; 150:17-23.

de Lonlay P, Seta N, Barrot S, et al. A broad spectrum of clinical presentations in congenital disorders of glycosylation I: a series of 26 cases. J Med Genet 2001; 38: 14-9.

Drouin-Garraud V, Belgran M, Grunewald S, et al. Neurological presentation of a congenital disorder of glycosylation CDG-la: implications for diagnosis and genetic counseling. Am J Med Genetics 2001; 101:46-9.

Dupré T, Vuilamier-Barrot S, Chantret I, et al. Guanosine diphosphate-mannose: GlcNAc2-PP-dolichol mannosyltransferase deficiency (congenital disorders of glycosylation type Ik): five new patients and seven novel mutations. J Med Genet 2010; 47: 729-35.

Dulac O, Soufflet C, Chiron C, Kaminska A. What is West syndrome? Int Rev Neurobiol 2002; 49:1-22.

Fiumara A, Barone R, Del Campo G, et al. Electroclinical features of early-onset epileptic encephalopathies in congenital disorder of glycosylation (CDGs). JIMD Rep 2016; 27: 93-9.

Fois A. Infantile spasms: review of literature and personal experience. Ital J Pediatr 2010; 36: 15.

Freeze HH, Eklund EA, Ng BG, Patterson MC. Neurology of inherited glycosylation disorders. Lancet Neurol 2012; 11 : 453-66.

Funke S, Gardeitchik T, Kouwenberg D, et al. Perinatal and early infantile symptoms in congenital disorders of glycosylation. Am J Med Genet Part A 2013;161A: 578-84.

Grubenmann CE, Frank CG, Hulsmeier AJ, et al. Deficiency of the first mannosylation step in the $\mathrm{N}$-glycosylation pathway causes congenital disorder of glycosylation type Ik. Hum Mol Genet 2004; 13(5): 535-42. 
Haeuptle MA, Hennet T. Congenital disorders of glycosylation: an update on defects affecting the biosynthesis of dolichol-linked oligosaccharides. Hum Mutat 2009; 30(12): 1628-41.

Helander A, Stodberg T, Jaeken J, et al. Dolichol kinase deficiency (DOLK-CDG) with a purely neurological presentation caused by a novel mutation. Mol Gen Metab 2013;110(3): 342-4.

Ishikawa N, Tajima J, Ono H, Kobayashi M. Different neuroradiological findings during two stroke-like episodes in a patient with a congenital disorder of glycosylation type la. Brain Dev 2009; 31(3): 240-3.

Jaeken J, Vanderschueren-Lodeweyckx M, Casaer P, et al. Familial psychomotor retardation with markedly fluctuating serum proteins, FSH and GH levels, partial TBG-deficiency, increased serum arylsulphatase-A and increased CSF protein: a new syndrome? Pediatr Res 1980;14: 179.

Jaeken J. Congenital disorders of glycosylation. Ann NY Acad Sci 2010; 1214: 190-8.

Jaeken J, Hennet T, Matthijs G, Freeze HH. CDG nomenclature: time for a change! Biochim Biophys Acta 2009; 1792: 825-6.

Jaeken J. Congenital disorders of glycosylation. In: Saudubray JM, Baumgartner MR, Walter J. Heidelberg. Inborn Metabolic Diseases - Diagnosis and Treatment. 5th Edition. SpringerVerlag Berlin, 2012 : 608-16.

Jaeken J, Lefeber D, Matthijs G. Clinical utility gene card for: ALG6 defective congenital disorder of glycosylation. Eur J Hum Genet 2015; 23(2).

Kranz C, Denecke J, Lehle L, et al. Congenital disorders of glycosylation type Ik (CDG-lk): a defect of mannosyltransferase I. Am J Hum Genet 2004; 74: 5454-551.

Morava E, Wosik H, Kártezi J, et al. Congenital disorder of glycosylation type Ix: review of clinical spectrum and diagnostic steps. J Inherit Metab Dis 2008; 31: 450-6.
Millón MBB, Delgado MA, Azar NB, et al. Two Argentinean siblings with CDG-Ix: a novel type of congenital disorder of glycosylation? J Inherit Metab Dis 2011;18: 65-72.

Noh GJ, Asher JT, Graham JM. Clinical review of genetic epileptic encephalopathies. Eur J Med Genet 2012;55(5): 281-98.

OMIM (Online Mendelian Inheritance in Man) database. http://www.omim.org/

Rahman S, Footitt E, Varadkar S, Clayton P. Inborn errors of metabolism causing epilepsy. Dev Med Child Neurol 2013; 55: 23-36.

Rind N, Schmeiser V, Thiel C, et al. A severe human metabolic disease caused by deficiency of the endoplasmatic mannosyltransferase hALG11 leads to congenital disorder of glycosylation-Ip. Hum Mol Genet 2010;19(8): 1413-24.

Schwarz M, Thiel C, Lubbenhusen J, et al. Deficiency of GDP-Man:GlcNAc2-PP-dolichol mannosyltransferase causes congenital disorder of glycosylation type Ik. Am J Hum Genet 2004; 74: 472-81.

Sun L, Eklund EA, Van Hove JLK, et al. Clinical and molecular characterization of the first adult congenital disorder of glycosylation (CDG) type Ic patient. Am J Med Genet 2005; 137A: 22-6.

Thiel C, Rind N, Popvici D, et al. Improved diagnostic lead to identification of three new patients with congenital disorder of glycosylation-lp. Hum Mutat 2012;33(3): 485-7.

Vodopiutz J, Bodamer OA. Congenital disorders of glycosylation - a challenging group of IEMs. J Inherit Metab Dis 2008; 31: 267-9.

Wolf N, Bast T, Surtees R. Epilepsy in inborn errors of metabolism. Epileptic Disord 2005;7(2): 67-81.

\section{TEST YOURSELF}

(1) Are epileptic spasms a possible feature in glycosylation disorders? If yes, for which subtype(s) have they been described?

(2) What other epileptic manifestations can be associated with spasms in non-la congenital disorders of glycosylation patients?

(3) What are the particular electroclinical patterns associated with spasms in non-la congenital disorders of glycosylation?

Note: Reading the manuscript provides an answer to all questions. Correct answers may be accessed on the website, www.epilepticdisorders.com, under the section "The EpiCentre". 